\title{
THE PRICE LEVEL.
}

The Purchasing Power of Money. Its Determination and Relation to Credit, Interest and Crises. By Inving Fisher. Assisted by Harry G. Brown. New York, The Macmillan Company, 1911. xxii+505 pages.*

A LONG-CONTINUED and extensive rise or fall in the general level of prices brings on a serious disarrangement of the status of parties to long time contracts involving payments of fixed or nearly fixed sums of money, unbalances the economic equilibrium which is never too stable, and develops in its wake various extreme political doctrines. The extended decline of prices from the seventies to the nineties of the past century worked hardship to those who had borrowed money in the earlier part of the period and had to repay the money with interest during the latter part of the period when their produce brought a reduced sum of money per unit. Hence populism and free silver. The succeeding great rise in prices, which has now run for nearly twenty years with no immediate prospect of cessation, is working a like hardship on the wage-earning and salaried classes, whose income does not rise nearly so fast as the prices of the articles they consume. Hence socialism, the single tax, and the like.

It would work for greater justice and contentment all around if the general level of prices could be kept more or less constant. Moreover, changing prices give to the brighter, to the more wide-awake, often to the merely luckier members of society an advantage for profit over their more stupid or unfortunate brethren. This is distinctly undemocratic; for, as Emile Faguet so brilliantly points out, $\dagger$ the worship of democracy is the cult of incompetence. It is an old-fashioned, unprogressive idea, perhaps, but still an idea widely held by thoughtful persons that prices cannot be maintained for any long period in defiance of economic laws, that on the contrary the desirable constancy of the level of prices can only be worked out by a painstaking study of and compliance with those laws.

\footnotetext{
* For a review of the earlier works, Capital and Income, and Rate of Interest, written in a similar spirit and helpful, though not necessary, to the understanding of the present work, see this Bulletin, vol. 15, p. 169.

$\dagger$ The Cult of Incompetence, New York, Dutton, 1912.
} 
In the Purchasing Power of Money, Fisher makes a detailed, systematic, scientific study of the causes affecting the general price level, and with this as a basis he makes some tentative suggestions, which he has modified and worked out in greater detail in more recent monographs, for the stabilization of the purchasing power of money. These suggestions have attracted widespread attention and comment; they have been cordially applauded and seriously combatted, often, we daresay, by persons who have neglected the main part of the author's text; but we shall pass them over and, indeed, confine our attention chiefly to one point of mathematical interest in the volume. $\dagger$

To get a quantitative basis for the treatment of prices we may equate expenditures and the money-value of goods bought. Thus

$$
M V+M^{\prime} V^{\prime}=P T,
$$

where $M$ is the quantity of money in circulation and $V$ the velocity of circulation ( $M V$ giving expenditures in cash), $M^{\prime}$ the quantity of deposits subject to check and $V^{\prime}$ their velocity of circulation $\left(M^{\prime} V^{\prime}\right)$ giving the total expenditure by check), $T$ the total amount of trade, and $P$ the average price. Certain general conclusions follow from this equation. For instance, if the amount of trade increases, while $M, V, M^{\prime}, V^{\prime}$ remain constant, the price level must fall; if $M$ and $T$ increase proportionately, while $V$ and $V^{\prime}$ remain constant, $P$ will decrease or increase according as $M^{\prime}$ increases more slowly or more rapidly than $M$ and $T$.

Various consequences are readily obtained from the equation of exchange (1), but the determination of the equation itself is not so easy as it might look to a careless thinker. The difficulties lie in the fact that $P$ and $T$ individually are quite indeterminate. An average price level $P$ means nothing until the rules for obtaining the average are specified, and independent rules for evaluating $P$ and $T$ may not satisfy (1). For instance suppose sugar is $5 \mathrm{c}$. a pound, bacon 20c. a pound, coffee $35 \mathrm{c}$. a pound. The average price is $20 \mathrm{c}$. If a person buys $10 \mathrm{lbs}$. of sugar, $3 \mathrm{lbs}$. of bacon, and $1 \mathrm{lk}$. of coffee, the total trading is in $14 \mathrm{lbs}$. of goods. The total expenditures is $\$ 1.45$;

* See, for example, recent numbers of the American Economic Review. $\uparrow$ For a review of some other aspects see Science, May 16, 1913, p. 758. 
the product of the average price by the total trade is $\$ 2.80$; the equation of exchange is very far from satisfied.

After thinking this example over one might come to the conclusion that nobody would use such a crude method of averaging prices. The method is, however, the simplest and most obvious and is widely used. Bradstreet's much quoted index of 96 commodities is (see page 417) an average of prices per pound; relatively small and unimportant changes in the prices of expensive articles may entirely mask relatively large movements in the prices of cheap articles. Despite the crudeness of the average for $P$ it is possible, of course, to satisfy the equation of exchange by defining the measure of $T$ as

$$
T=\frac{M V+M^{\prime} V^{\prime}}{P} .
$$

In the above example with an average price per pound of $20 \mathrm{c}$. the total trade would be $7 \frac{1}{4} \mathrm{lbs}$. If the trade were measured as $14 \mathrm{lbs}$., the average price would have to be about $10 \frac{1}{3} \mathrm{c}$.

The difficulty of reconciling with equation (1) an average price and a total trade, each evaluated independently by natural methods, is great and requires a searching analysis of what is meant by an average and what is really natural and reasonable. There are other difficulties. One of them I came across a few years ago when trying to help a friend make a stock-average which would be representative of prices on the New York Exchange from 1872 to date. It was impossible to find ten stocks that had remained active and representative over so long a period, and the initial list of ten had to be modified by several successive changes. In the same way if any average of commodity prices contains articles which go out of consumption entirely or to any very great extent, there is a discontinuity introduced in $P$, and a good index $P$ should satisfy the condition of allowing one article to be replaced by another.

The mathematical interest in Fisher's work lies chiefly in the discussion of the theory of averages with especially reference to the determination of the best form of index number for prices and trade. This is applied, not pure, mathematics; the analysis aids in forming the judgment but is not determinative, for no index number is found to satisfy all the tests which are desired. Forty-four different indices are comparatively dis- 
cussed. The treatment of these matters is for the most part relegated to a long appendix to Chapter $\mathrm{X}$. In itself it constitutes a notable contribution to political arithmetic.

The general course of the text may be summarized as follows. After some preliminary definitions (Chapter I), the author treats the simple case $M V=P T$ of the equation of exchange which would arise under a financial system with no checking accounts, and determines particularly the relation of the quantity of money $M$ to the price level $P$. He then (Chapter III) generalizes so as to include the term $M^{\prime} V^{\prime}$ and the effect of deposit currency. At the close of the chapter he has come to the conclusion that normally the available currency is apportioned between $M$ and $M^{\prime}$ in a certain more or less definite, even though elastic, ratio. This conclusion is the result of forming a judgment, it is not deductively obtained; the statistics given for this country from 1896 to date show a progressive increase of the ratio $M^{\prime} / M$, and recent statistics for other countries would probably show the same tendency. We can retain the conclusion only by assuming that for a couple of decades conditions have not been normal. The advantage of including the constancy of $M^{\prime} / M$ among our axioms is that we thereby restore theoretically and normally the proportionality between $M$ and $P$ which has for all practical purposes been entirely upset by the recent great increase in the ratio $M^{\prime} V^{\prime} / M V$.

In Chapter IV transition periods are analyzed; it is here, chiefly, that justification for the subtitle referring to credit, interest and crises, may be found. The next two chapters analyze a number of influences which indirectly affect the purchasing power, and Chapter VII deals with the influence of monetary systems. The eighth chapter, on the effect of the quantity of money and other factors on purchasing power and on each other, touches many topics but is chiefly directed toward showing $\left(1^{\circ}\right)$ that the price level $P$ is the passive element, the effect, the dependent variable in the equation of exchange and not the cause, and $\left(2^{\circ}\right)$ that the special quantity theory that variations in $M$ normally produce proportional changes in $P$ is true.

There are so many bitter and blind opponents to any specific theory (and the quantity theory is no exception) that an author who has to qualify the fundamental proposition of his theory by so vague a restriction as "normally" might do well to 
use the term hypothesis in place of theory; and he can certainly not spend too much pains on separating those portions of his work which depend upon such a hypothesis from those which do not.

Chapter IX shows the necessity for an index of prices, and Chapter X, aided by the long mathematical appendix previously reviewed, seeks after the best index. Statistical matter bearing on the previous text now fills two chapters, and the text closes with the discussion of the possibility of keeping the general price level more nearly constant. There are numerous appendices and a very full index.

To the mathematician Fisher's work always appears more sympathetic than that of many of his economic colleagues by virtue of its greater respect for logical and numerical values. This latest book is no exception.

Edwin Bidwell Wilson.

Massachusetts Institute of Technology.

\section{SHORTER NOTICES.}

Vorlesungen über Geometrie, mit besonderer Benutzung der Vorträge von Alfred Clebsch, bearbeitet und herausgegeben von Dr. Ferdinand Lindemann. Zweite, vermehrte Auflage. Leipzig, Teubner. I Band, I Teil, 1 Lieferung, 1906, vi + 480 pp.; 2 Lieferung, 1910, 288 pp.

THIs revised edition of Clebsch's inimitable and classical lectures is much more than a reprint of the first edition which appeared in 1875-76. Much has been done since then to enrich the subject, and Dr. Lindemann has done well to include the most important of these researches in this revision. The extent of the additions to the text may be seen from a comparison of the number of pages for Part I; this includes the same general subjects in the two editions and yet covers about three times as many pages in the second as in the first (the size of the type and the page differ only slightly). If this ratio is upheld in the other parts, Volume I will contain about 3,000 pages of text.

It is unfortunate that four years should elapse between the two installments. Upon the appearance of the first installment, the completion of Part I was promised within a few 